\title{
Cirugía por mínima incisión de los dedos menores
}

\author{
Minimally invasive surgery of the lesser toes \\ Joan Lozano Freixas ${ }^{1}$ y Luis Castillo Sánchez ${ }^{2}$ \\ ${ }^{1}$ Clínica Freixas, Barcelona, España. ${ }^{2}$ Clínica PodoDent, Barcelona, España
}

Palabras clave:

Cirugía por mínima incisión, cirugía percutánea digital, cirugía digital, dedo en martillo, dedo en garra, deformidad digital, MIS falanges digitales.

\section{Resumen}

Con este trabajo se pretende dar una actualización y opinión sobre los diferentes procedimientos en cirugía MIS para la corrección de la patología digital mediante la descripción e indicación de las diferentes técnicas, así como la evolución de las mismas. Las técnicas originales en cirugía MIS para la corrección de la patología digital fueron las osteotomías completas; a continuación se adaptaron de la cirugía a campo abierto la artroplastia y la artrodesis por MIS, para más tarde desarrollar las osteotomías incompletas, en las que una parte de la cortical ósea se deja intacta. En sus inicios era indispensable la cirugía sobre tejidos blandos, tenotomías y capsulectomías como parte de la cirugía digital. Hoy en día en las actuaciones digitales, según el grado de deformidad y edad del paciente, se intenta evitar la cirugía sobre tejido blando y corregir la deformidad mediante la actuación en tejido óseo para evitar la deficiencia de movilidad postoperatoria que se produce al realizar tenotomías.

\begin{abstract}
This study aims to update the various minimally invasive procedures when surgically restoring the normal alignment of the lesser toes and also provides the opinion of the author. This is done through the description and indication of the different MIS techniques and their evolution over time. The first lesser toe MIS procedures were initially performed in a complete osteotomy treatment. Over the years, this alternative was expanded into arthroplasties and arthrodesis surgeries, both commonly used as open methods and finally the minimally invasive correction was practised on partial osteotomies where a portion of the cortical is retained. In the past, lesser toe surgery procedures always involved soft tissue damage, tenotomies and capsular release. Nowadays, based on the type of the deformity and patient age, soft tissue work is avoided and the corrective surgery is preferably done through bone structure treatment strategies instead. This option is carried out to minimise the longer recovery time and mobility impairment associated with tenotomies.
\end{abstract}




\section{INTRODUCCIÓN}

La cirugía de mínima incisión del pie, o cirugía MIS (proviene del inglés Minimally Invasive Surgery), tiene sus inicios en los Estados Unidos de América por los podólogos americanos, cuando en 1945 el Dr. Morton Polokoff desarrolló un sistema de cirugía subdérmica utilizando unos bisturís y limas muy finas. Hacia el año 1965 el Dr. Albert Brown empezó a eliminar los espolones de calcáneo con una cureta para hueso de $6 \mathrm{~mm}$, disminuyendo de forma importante la vía de acceso que se había utilizado hasta entonces. En 1967, el Dr. Joseph Addante realizó las osteotomías de los metatarsianos a través de incisiones de menor tamaño al que se realizaban en la cirugía a campo abierto.

El Dr. Michael Perrone publicó el primer libro sobre cirugía ósea del pie utilizando una turbina con limas, evidenciando la primera referencia de instrumental motorizado utilizado en estas técnicas. El Dr. Hymes impartió las primeras conferencias de cirugía MIS, y Leonard Britton realizó la osteotomía de Akin sin prácticamente abertura hacia el año 1972. En 1986, el Dr. Blair M. Bycura publicó un atlas muy completo sobre la cirugía de mínima incisión del pie y, en 1991, el Dr. Dennis L. White editó un volumen completo sobre MIS en Clinics in Podiatric Medicine and Surgery, donde se encuentra la modificación de la osteotomía capital de $1 .{ }^{\text {er }}$ radio de Reverdin Ilevada a cabo por el Dr. Stephen Isham. En España, Luis Aycart introdujo las técnicas de MIS del pie, después de la experiencia que adquiere en sus estancias en Estados Unidos en 1969. La publicación del artículo "Mini cirugía del dedo en martillo" por Luis Aycart en la Revista Española de Podología supone la primera referencia escrita existente de la cirugía MIS en lengua española. Posteriores visitas a España del Dr. Albert Brown fueron seguidas con entusiasmo por los miembros de la recién formada Academia de Cirugía Ambulatoria del Pie, compuesta por un grupo de podólogos pioneros, que se autoforman entre sus asociados bajo la dirección de Javier Aycart y Manuel San Juan, que son quienes introducen las técnicas de cirugía MIS del pie en España y en Europa.

En los años 90, Francisco Muñoz Piqueras presidió la Asociación de Cirugía Ambulatoria del Pie (ACAP), después de pasar largas temporadas en los Estados Unidos formándose con el Dr. Stephen Isham, auténtico innovador y revolucionario de estas técnicas; posteriormente se fundó la Asociación Española de Cirugía por Mínima Incisión (AEMIS) por D. José Aguilar en el año 2000.

La cirugía podológica por mínima incisión del pie puede ser definida como aquellos procedimientos quirúrgicos en los que actuamos mediante pequeñas incisiones para solucionar la patología presente procediendo con la indicación de la técnica, protocolo quirúrgico instaurado, aparatología apropiada e instrumental específico.

Mayoritariamente, la cirugía MIS la empleamos en:

- La patología del antepié, siendo muy versátil en sus procedimientos, en especial en la cirugía digital que, por sus características, se presenta en muchas ocasiones como la técnica indicada, como en el pie diabéti$\mathrm{co}$, minimizando en especial complicaciones de origen infeccioso y de curación de heridas quirúrgicas por su pequeña incisión.

- En el pie artrítico, donde es probable una reintervención con el tiempo por su enfermedad, pudiendo volverse a reintervenir en estructuras que ya han sanado tras su consolidación y sin el contratiempo de la osteosíntesis (ya que por norma general no se requiere).

- En patología vascular específica de origen venoso, evitando las complicaciones asociadas al uso del torniquete.

Según la clasificación de la ASA del paciente (American Society of Anesthsiologists) e idiosincrasia del mismo, puede ser complementaria a otros procedimientos por técnica abierta e, incluso, siendo compatible con la osteosíntesis si se precisa.

Para proceder a dichos procedimientos resulta imprescindible el conocimiento anatómico, la fisiología ósea de la consolidación indirecta (base de la consolidación de las osteotomías) y de alternativas de técnicas por exposición en caso de ser requeridas, siendo muy ilustrativo el libro de Atlas de cirugía del antepié ${ }^{1}$ (Figuras 1 y 2).

La evolución de estos procedimientos se plasma especialmente por el desarrollo realizado desde la asociación científica AEMIS, que desde años viene formando a numerosos podólogos con los procedimientos reglados y consensuados por los diferentes profesionales especializados en estas técnicas, incorporando protocolos y algoritmos de indicaciones en las técnicas. Esto se recoge en el primer libro especializado en cirugía MIS editado en España Cirugía podológica. Técnicas por mínima incisión?

En su conjunto, la cirugía podológica presenta un gran avance por el incremento de podólogos cirujanos que se incorporan a esta disciplina; de ello se deriva la necesaria actualización de los procedimientos actuales plasmados en el último libro editado en España de cirugía, coordinado por E. Nieto y con la colaboración transversal de diferentes autores (podólogos, podiatras y traumatólogos) tanto de ámbito nacional como internacional expertos en cada materia ${ }^{3}$.

\section{LA APORTACIÓN DE LA CIRUGÍA MIS A LA CIRUGÍA PODOLÓGICA}

La MIS ha abierto un campo de actuación en diferentes tipos de patologías que pueden ser resueltas de una manera poco agresiva para el paciente y con procedimientos sencillos en su ejecución, como las pequeñas exostosis, permitiendo al podólogo su primer contacto con el tejido óseo.

Su aplicación en la cirugía de los dígitos menores hace que, en la medida de lo posible, sea la técnica de elección. Una de sus principales características es su gran versatilidad, permitiendo actuar en partes blandas, preservar articulaciones mediante las osteotomías, generar pseudoarticulaciones con 


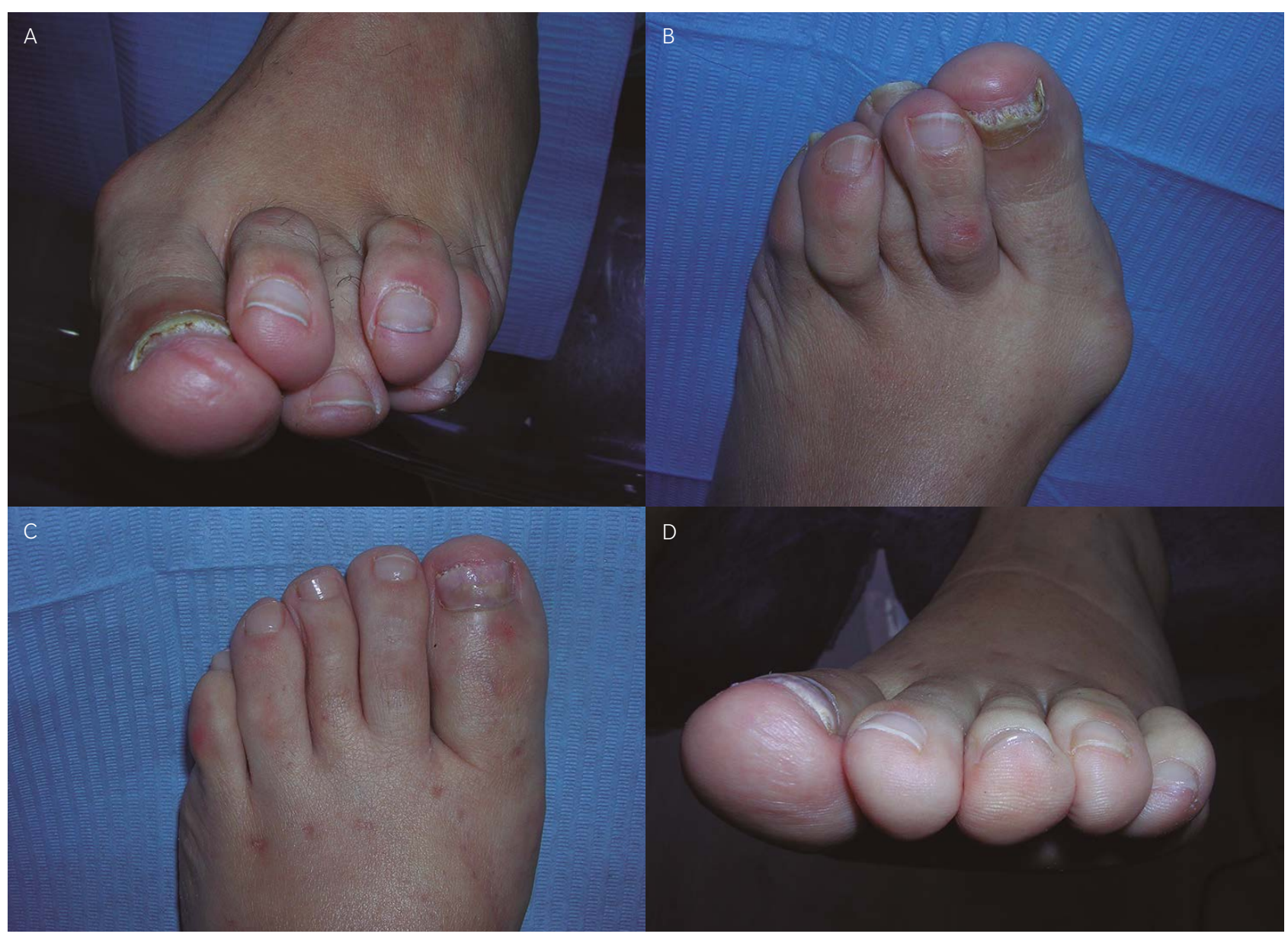

Figura 1. A. Actuación de multitécnica por MIS mediante osteotomías en la deformidad del antepié con uso de osteosíntesis temporal.

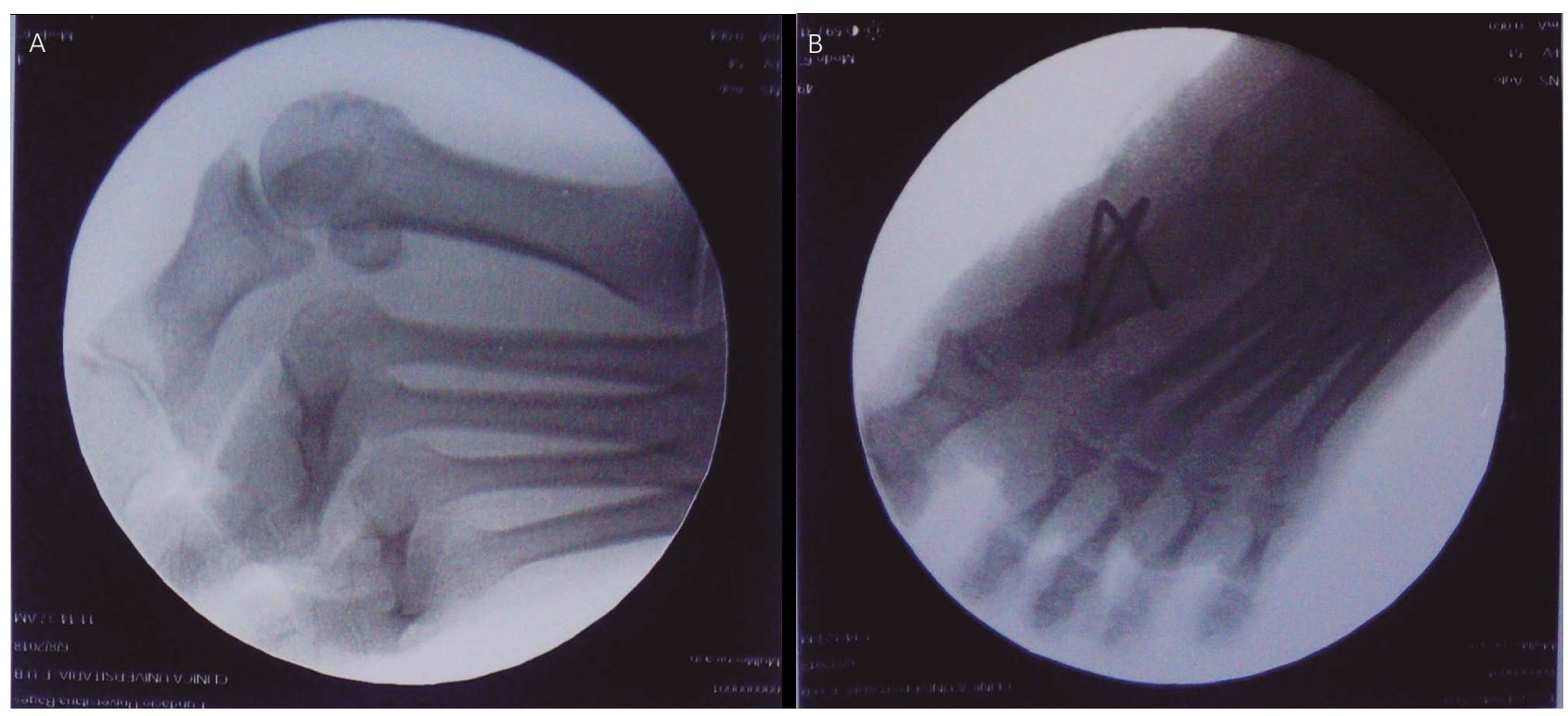

Figura 2. El fluoroscopio es un aparato imprescindible en la cirugía MIS. Imagen y comprobación fluoroscópica de la intervención realizada. 
la artroplastia y fusiones articulares con la artrodesis. Con estos procedimientos y las diferentes deformidades digitales desarrollaremos los diferentes tratamientos y sus indicaciones.

\section{CARACTERÍSTICAS DE LA CIRUGÍA MIS}

La cirugía MIS tiene diferentes características, algunas de las cuales son comunes a la cirugía de campo abierto y otras son específicas de este conjunto de técnicas.

Principalmente, la cirugía MIS es un conjunto de técnicas que se realizan de forma ambulatoria mediante anestesia local, permitiendo la deambulación inmediata. Las técnicas quirúrgicas se efectúan sin hemostasia, evitando así todos los riesgos asociados al torniquete o vasoconstrictor para realizar isquemia. Es una cirugía que se hace a través de pequeñas vías de acceso $(0.1 \mathrm{~mm}-0.5 \mathrm{~mm}$ ) con el objetivo de minimizar el daño tisular y sus derivadas. No se suelen aplicar osteosíntesis salvo en casos específicamente indicados. La localización y el diseño específico de las osteotomías, junto a la realización de vendajes postoperatorios, van a ofrecer la estabilidad relativa de las osteotomías y mantener la corrección necesaria de los segmentos óseos.

\section{CONCEPTOS PARA EL CIRUJANO QUE VAYA A DESARROLLARLA}

Visión de los planos de actuación en las osteotomías

En la realización de las técnicas quirúrgicas en cirugía MIS se debe tener en cuenta los tres planos del espacio frontal, sagital y transversal, ya que las deformidades digitales se pueden dar en uno o en varios planos a la vez, por lo tanto, el correcto diagnóstico de la deformidad digital en cada uno de los planos va a servir de guía para la elección de la técnica a realizar y los gestos quirúrgicos para llevar a cabo la corrección de la deformidad, pudiendo optar por combinación de técnicas entre sí.

Se debe tener una buena orientación tridimensional, y además de los planos anteriormente comentados, nos guiaremos por el eje medio del cuerpo y el eje medio del segmento óseo a la hora de realizar la osteotomía en forma de cuña, basándonos en la teoría de los cuadrantes, por lo que si observamos la falange desde una visión frontal y la dividimos en cuatro partes iguales, obtendremos dos cuadrantes dorsales y dos plantares; dependiendo de los cuadrantes sobre los que actuemos, reorientaremos la falange y corregiremos su deformidad (Figura 3).

\section{Vendaje}

Los vendajes en cirugía MIS son muy importantes y específicos, ya que tienen como objetivo cerrar las osteotomías y mantener la corrección del segmento óseo y del dígito en sí.
El vendaje se divide en diferentes capas, siendo la primera capa del vendaje la más importante, ya que está en contacto con la piel, y mediante unas tiras y corbatas se consigue el cierre de las osteotomías manteniendo la corrección de los segmentos óseos.

\section{Cicatrización ósea}

El fundamento esencial de la cirugía MIS se basa en la consolidación ósea secundaria ya que, a priori, no precisa elementos de osteosíntesis, por lo que obtenemos inicialmente una estabilidad relativa. Por este motivo es imprescindible el conocimiento fisiológico de la consolidación ósea, así como la realización de un vendaje efectivo y control postoperatorio fluoroscópico para evaluar la correcta evolución quirúrgica. En cirugía digital es recomendable el mantenimiento del vendaje y calzado postoperatorio al menos un mes, tiempo necesario en la formación del callo óseo blando o primario, pudiendo mantenerse varias semanas más para facilitar la distensión de la piel y que ésta se adecue a la nueva disposición.

\section{METODOLOGÍA}

Para el desarrollo del manuscrito y complementación de los criterios aportados se ha realizado una búsqueda lenguaje libre (palabras claves) y lenguaje controlado (descriptores Mesh) a través de las siguientes bases de datos y metabuscadores: PubMed, Cinahl, Crochane y Cuiden. Se utilizaron los siguientes booleanos AND y OR combinados con criterios de búsqueda libre y con Mesh.

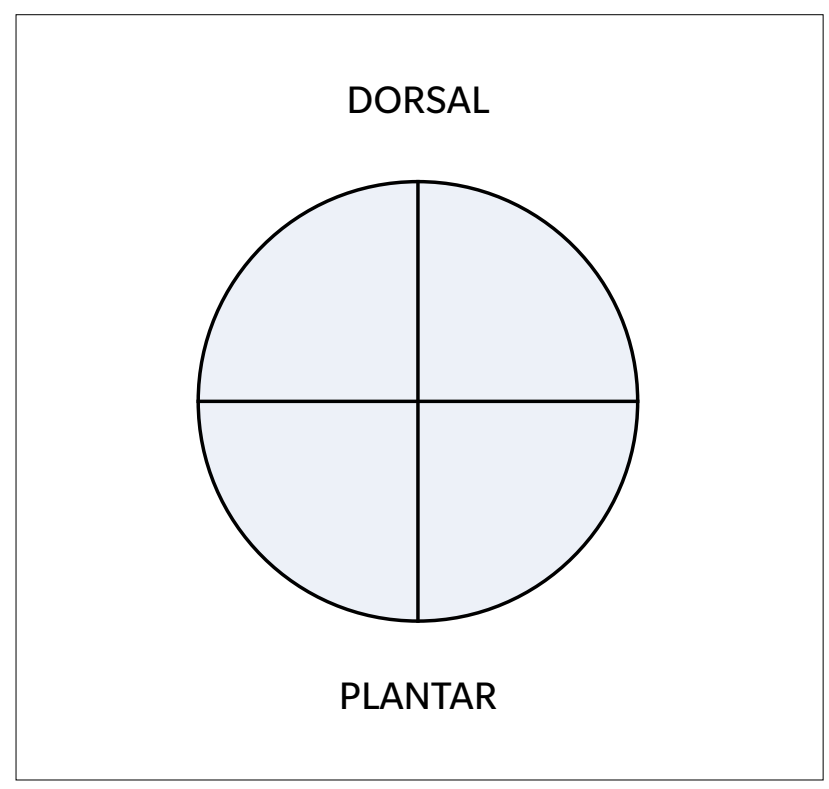

Figura 3. Distribución de los cuadrantes desde un plano frontal. 
Palabras utilizadas en lenguaje libre: cirugía por mínima incisión, cirugía percutánea digital, cirugía digital, dedo en martillo, dedo en garra, deformidad digital, MIS, falanges digitales.

Descriptores Mesh (DESC) utilizados: hammertoe, minimaIly invasive surgery procedures, adverse effects, ambulatory surgical procedures, podiatry.

Finalmente se realizó una búsqueda libre en Google academic y bibliografía propia de literatura.

\section{PATOLOGÍA DIGITAL EN LOS DEDOS MENORES}

En los dedos menores encontramos patologías muy diversas, en su mayoría con una afectación retrógrada sobre la articulación metatarsofalángica (MTTF), siendo un componente a valorar en la cirugía y cuya finalidad principal es la realineación MTTF, debiendo actuar sobre esta estructura si se precisa. Mencionada la importancia de la actuación metatarsodigital, nos centraremos exclusivamente en la cirugía digital.

\section{EVALUACIÓN DE LA DEFORMIDAD Y SU CLASIFICACIÓN}

La valoración de la deformidad y su clasificación es posible mediante diversas maniobras exploratorias y test.

- Test de Kelikian: valora el grado de reducción de la deformidad. Se realiza un movimiento en flexión dorsal (FD) en la zona retrocapital de los metatarsianos centrales simulando la carga, debiendo valorar la reductibilidad digital, siendo un resultado positivo en deformidades rígidas y negativo en deformidades flexibles ${ }^{4}$ (Figura 4).

- Valoración síndrome predislocación de la articulación MTTF: ocurre como resultado del debilitamiento de las estructuras periarticulares que estabilizan las articulaciones MTTF, especialmente del plato glenoideo. Los primeros en acuñar el nombra de síndrome de predislocación, como un síndrome tal, fueron Yu y cols. en el año $2002^{5}$ (Figura 5).

- Test de Lachman o prueba de estrés vertical: si existe un desplazamiento igual o superior a $2 \mathrm{~mm}$, se considera esta prueba positiva y esto sugiere que puede existir una rotura del plato plantar o plato glenoideo. Este test sirve para valorar el grado de subluxación o luxación de la articulación MTTF, la estabilidad de la misma y como se ha comentado, el estado de la placa plantar (Figura 6).

- Movilidad de la articulación interfalángica proximal (IFP) e interfalángica distal (IFD), clasificándola en flexible semirrígida o rígida.

- Localización de la deformidad: articulación MTTF, articulación IFP y/o articulación IFD.

- Plano de la deformidad: longitudinal: dedo en martillo, garra proximal o distal (dedo en maza). Lateral: clinodactilia, infraducción y supraducción.
- Componente de la deformidad: morfológico: en especial la longitud, hipertrofia de la cabeza falange proximal y excrecencias óseas. Funcional: deformidad presente en estática, dinámica o ambas.

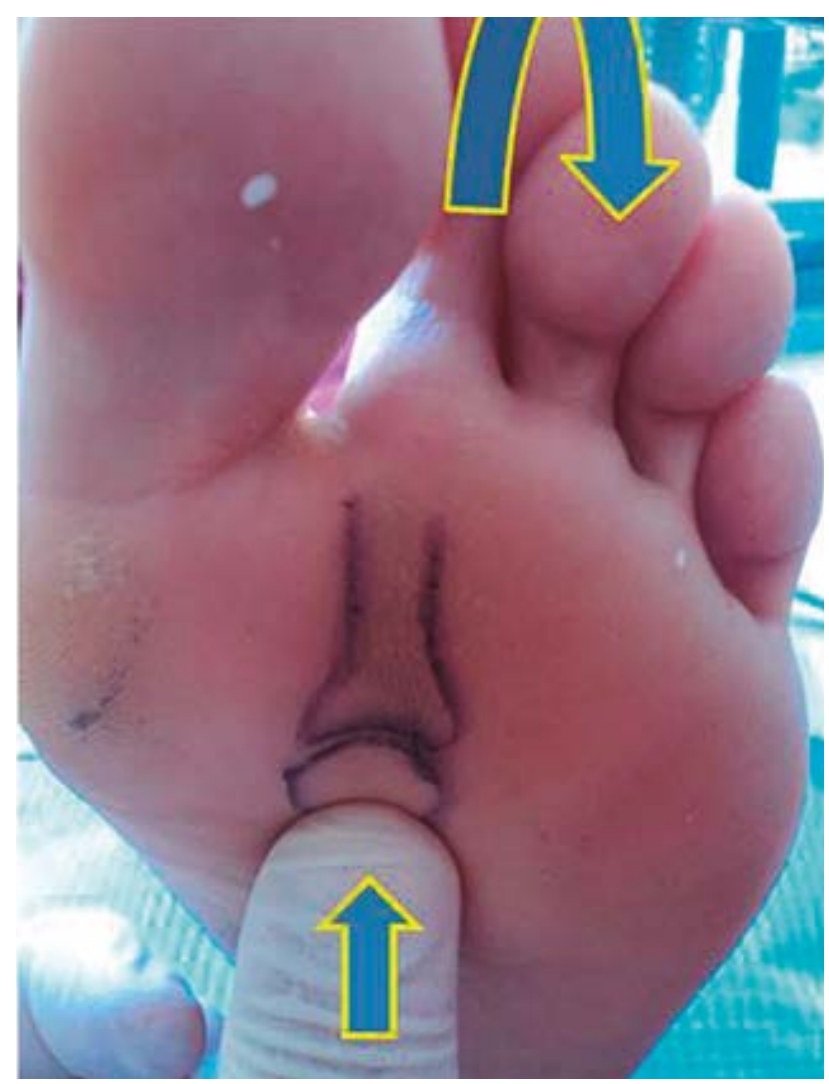

Figura 4. Maniobra test de Kelikian. Se realiza presión a nivel retrocapital, debiendo valorar la reductibilidad digital.

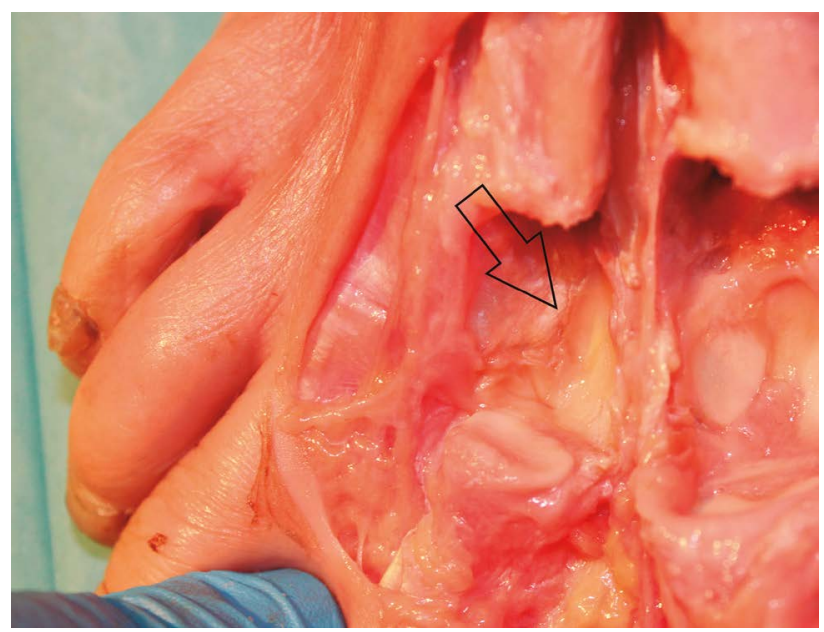

Figura 5. Pieza anatómica con visión del plato glenoideo. Apréciese el tejido nacarado correspondiente al plato glenoideo o placa plantar extirpada la cabeza metatarsal. 


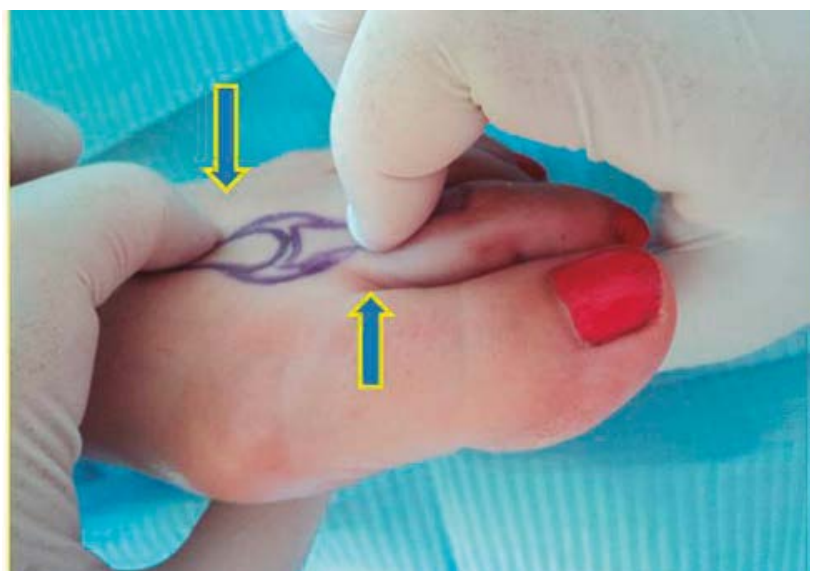

Figura 6. Test de Lachman. Ejecución de prueba de estrés vertical la mano pasiva estabiliza la cabeza metatarsal y la mano activa ejecuta movimiento de flexión dorsal del dígito.
Obtenidos los resultados de evaluación y clasificación podemos incluir el criterio quirúrgico más apropiado en cada caso (Tabla I).

\section{TÉCNICAS E INDICACIONES}

\section{Técnicas sobre partes blandas}

La actuación sobre partes blandas en la cirugía digital por MIS va a ser principalmente las tenotomías extensoras y flexoras, además de las capsulectomías en las articulaciones MTTF e interfalángicas, en caso de que sea necesario. Dependerá de cada deformidad digital la necesidad o no de actuar sobre partes blandas, aunque las últimas tendencias en cirugía MIS intentan preservar dichas estructuras para evitar la pérdida de movilidad digital que ello conlleva.

Tabla I. Procedimiento orientativo según clasificación del test de la deformidad.

\begin{tabular}{|c|c|c|c|}
\hline Test & Fases & Datos clínicos & Procedimiento \\
\hline \multirow[t]{2}{*}{ Kelikian } & Negativo: deformidad flexible & $\begin{array}{l}\text { Flexibilidad y corrección total o parcial de } \\
\text { la deformidad al simular carga }\end{array}$ & Osteotomías \\
\hline & Positivo: deformidad rígida & & Artroplastia, artrodesis \\
\hline \multirow[t]{3}{*}{ Lachman } & Inestabilidad AMTTF & $\begin{array}{l}\text { - Test de Lachman positivo } \\
\text { - Dolor mayor en especial en la fase } \\
\quad \text { propulsiva } \\
\text { - Edema dorsal } \\
\text { - Signos Rx inexistentes }\end{array}$ & $\begin{array}{l}\text { Actuación primaria en parte ósea y } \\
\text { valoración a posteriori de actuación } \\
\text { en partes blandas }\end{array}$ \\
\hline & $\begin{array}{l}\text { Fase de subluxación reductible } \\
\text { o semirreductible }\end{array}$ & $\begin{array}{l}\text { - Dolor exacerbado en dinámica } \\
\text { - Subluxación reductible } \\
\text { - Signos Rx muestran pinzamiento de la } \\
\text { interlínea articular }\end{array}$ & $\begin{array}{l}\text { Cirugía ósea digital. Actuación } \\
\text { adicional partes blandas sobre } \\
\text { la MTTF mediante tenotomías } \\
\text { flexoextensoras. }\end{array}$ \\
\hline & Lesión irreductible & $\begin{array}{l}\text { - Deformidad irreductible } \\
\text { - Mejor toleración al dolor } \\
\text { - Signos Rx en plano sagital y transverso }\end{array}$ & $\begin{array}{l}\text { Tenotomías flexoextensoras, capsu- } \\
\text { lectomía dorsal, cirugía ósea digital } \\
\text { y valoración osteotomía metatarsal }\end{array}$ \\
\hline \multirow[t]{3}{*}{$\begin{array}{l}\text { Movilidad articu- } \\
\text { lar digital }\end{array}$} & Reductible & $\begin{array}{l}\text { Inicio retracción partes blandas. No se } \\
\text { aprecia deformidad ósea }\end{array}$ & Osteotomía simple \\
\hline & Semirreductible & $\begin{array}{l}\text { Retracción partes blandas mantenidas con } \\
\text { alteración de planos de las falanges }\end{array}$ & $\begin{array}{l}\text { Osteotomías } \\
\text { Artroplastia (si hay hipertrofia de la } \\
\text { cabeza) }\end{array}$ \\
\hline & Irreductible & Fijación de la deformidad & Artroplastia/Artrodesis \\
\hline \multirow[t]{2}{*}{$\begin{array}{l}\text { Deformidad } \\
\text { planar }\end{array}$} & Longitudinal & $\begin{array}{l}\text { Dedo en martillo: articulación MTTF está } \\
\text { en FD, la IFP está en FP y la IFD está normal }\end{array}$ & $\begin{array}{l}\text { Doble osteotomía } \\
\text { Artroplastia } \\
\text { Tenotomías }\end{array}$ \\
\hline & Lateral & $\begin{array}{l}\text { Clinodactilia: desviación lateral de los } \\
\text { dedos en abducción o adducción } \\
\text { Supraducción: colocación del dedo encima } \\
\text { del otro } \\
\text { Infraducción: colocación del dedo debajo } \\
\text { del otro }\end{array}$ & $\begin{array}{l}\text { Osteotomía incompleta cierre } \\
\text { lateral } \\
\text { Osteotomía completa }\end{array}$ \\
\hline
\end{tabular}

AMTTF: articulación metatarsofalángica.FD: flexión dorsal. FP: flexión plantar. IFD: interfalángica distal. IFP: interfalángica proximal. MTTF: metatarsofalángica. Rx: radiológico. 
Tenotomías

Las tenotomías se van a realizar principalmente sobre los tendones de la musculatura extensora de los dedos, como es el extensor común de los dedos y el extensor corto común de los dedos o músculo pedio, y sobre los tendones la musculatura flexora digital, como es el flexor largo y corto común de los dedos.

\section{Indicación}

La justificación de las tenotomías será principalmente cuando exista una deformidad digital leve y reductible en la cual no sea necesaria la actuación sobre partes óseas, o bien cuando exista una deformidad severa e irreductible donde además de las técnicas sobre hueso sea necesaria la realización de las tenotomías. En cualquier caso, se debe valorar a cada paciente con su deformidad, teniendo en cuenta su idiosincrasia.

\section{Descripción técnica}

1. Para tenotomizar los tendones extensores se procede a realizar una vía de acceso de $1 \mathrm{~mm}$ con bisturí Beaver $67,2 \mathrm{~mm}$ distal a la articulación MTTF. Nos situamos subdérmicamente encima de los tendones y realizamos un movimiento de arriba hacia abajo hasta realizar la tenotomía (Figura 7).

2. Para realizar la tenotomía flexora, se efectúa una vía de acceso de $1 \mathrm{~mm}$ con bisturí Beaver 67 en el espacio subdiafisario a nivel de la falange proximal y se realiza un gesto de derecha a izquierda hasta completar la tenotomía (Figura 8).

\section{Capsulectomías}

La capsulectomía se realiza frecuentemente sobre la cápsula de la articulación MTTF de los radios menores, la cual puede ser dorsal, lateral y/o medial, y también sobre las cápsulas articulares de las articulaciones interfalángicas de los dedos menores, siendo en este caso mayormente plantar.

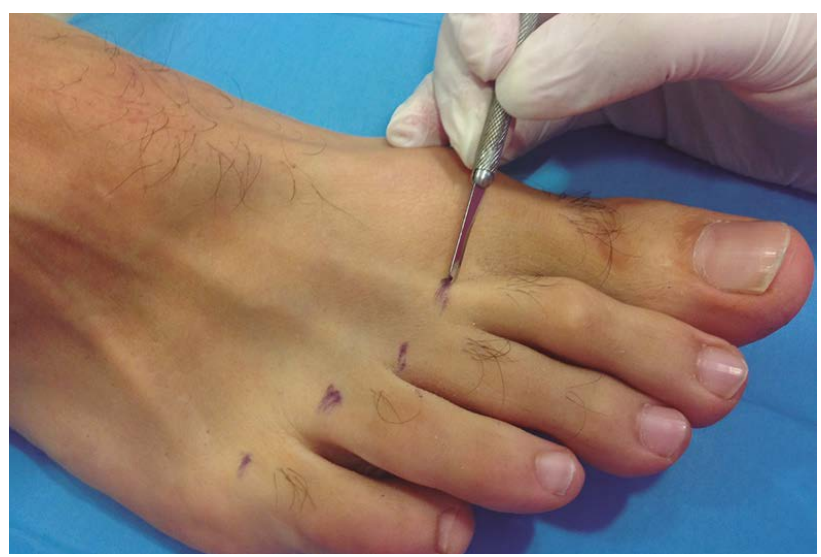

Figura 7. Localización de la vía de acceso para la tenotomía extensora.
Indicación

La capsulectomía MTTF se realiza cuando existe una subluxación o luxación MTTF, actuando en dorsal para la corrección del plano sagital (dedo en garra) o medial o lateral para corrección plano transversal (clinodactilias)

\section{Descripción técnica}

1. Para realizar la capsulectomía MTTF, se efectúa una vía de acceso de $2 \mathrm{~mm}$ con hoja de bisturí 64 dorsal en la interlínea articular MTTFy con un movimiento pendular se secciona la cápsula articular dorsalmente, lateral y/o medial, según sea necesario (Figura 9).

2. Para proceder a la capsulectomía interfalángica, se realiza una vía de acceso plantar de $1 \mathrm{~mm}$ con bisturí Beaver 67 en la interlínea articular de la articulación interfalángica y se secciona la cápsula articular.

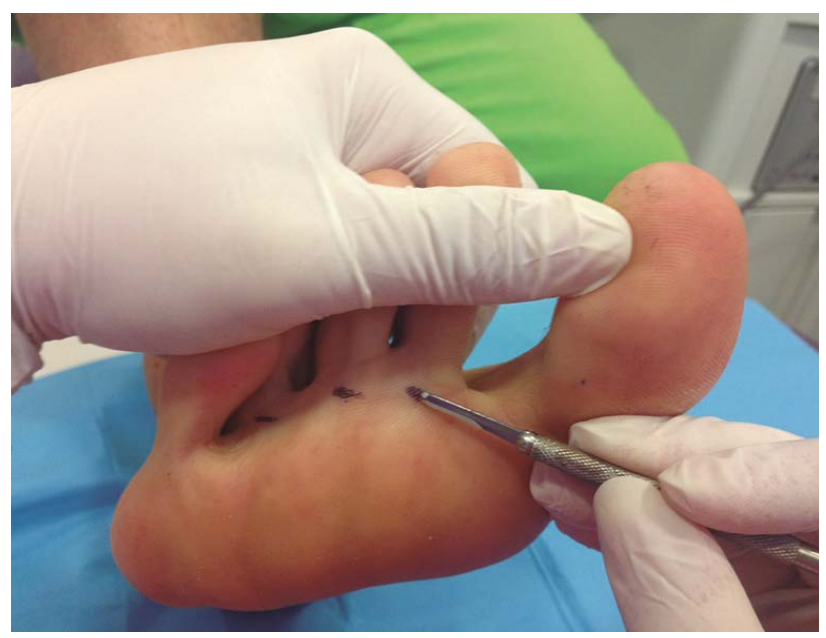

Figura 8. Localización de la vía de acceso para la tenotomía flexora. Fuente propia.

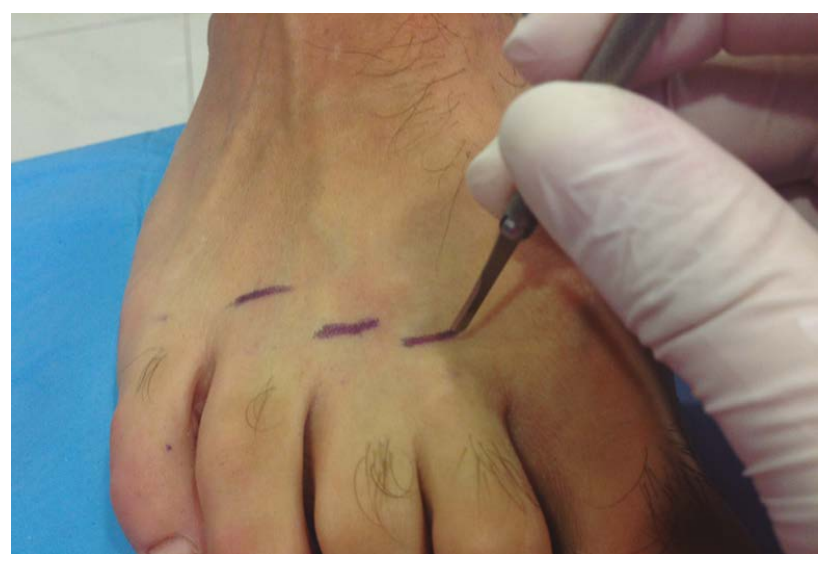

Figura 9. Localización de la vía de acceso para la capsulectomía MTTF. 


\section{Técnicas sobre estructuras óseas}

\section{Osteotomías}

Unas de las técnicas quirúrgicas para la corrección de las deformidades digitales son las osteotomías, las cuales pueden ser completas o incompletas.

Las osteotomías completas son una de las técnicas originarias de la cirugía MIS, fueron desarrolladas por el Dr. Brown y más adelante por el Dr. Bycura ${ }^{6}$, realizando osteotomías completas de las falanges para corregir las diferentes deformidades digitales. Más adelante, en el año 1995, José Antonio Teatino Peña introduce las osteotomías incompletas, desarrolladas después por Eduardo Nieto y colaboradores ${ }^{7,8}$.

\section{Osteotomías completas}

Indicación.

Las osteotomías completas están indicadas en casos en los que existe una deformidad severa y rígida del dedo, especialmente cuando este dígito es excesivamente largo y es necesario un acortamiento del mismo. Existen diferentes procedimientos mediante osteotomías completas para corregir una deformidad digital, doble o triple osteotomías, e incluso se pueden combinar con otros tipos de técnicas como las osteotomías incompletas, artroplastias por MIS o artrodesis.

\section{Técnica quirúrgica.}

Las osteotomías se van a realizar según el procedimiento escogido para la corrección de la deformidad y de distal a proximal.

\section{Doble osteotomía:}

1. Se efectúa una vía de acceso dorsolateral con hoja de bisturí Beaver 64 o 67 en el centro de falange media y con una fresa Shannon-Isham media o corta se realiza el corte total de la falange.

2. Se realiza una vía de acceso plantar con hoja de bisturí Beaver 64 o 67 en base de falange proximal y se realiza el corte de la falange con la fresa de lateral a medial.

Triple osteotomía:

El procedimiento es exacto al anterior, pero entre el paso $1 \mathrm{y}$ 2 se efectúa una osteotomía en la cabeza de falange proximal con acceso dorsolateral y corte de dorsal a plantar (Figura 10).

\section{Doble osteotomía en falange proximal:}

1. Se procede a efectuar una osteotomía en cabeza de falange proximal con vía de acceso dorso-lateral y corte de dorsal a plantar. A continuación, se realiza una segunda osteotomía en base de falange proximal mediante vía de acceso plantar y corte de lateral a contralateral (Figura 11).

\section{Osteotomías incompletas}

- Indicación.

Las osteotomías digitales incompletas (ODI) son como su nombre indica, incompletas en forma de cuña, manteniendo una parte del periostio de la falange sin cortar. Permiten corregir el eje de la falange y están indicadas en deformidades donde no se requiera un acortamiento del dígito, y donde no haya una deformidad severa del mismo. La realización de las ODI se basa en la teoría de los cuadrantes, por lo que la apertura de la cuña va a dirigir el cierre de la misma orientando el resto del segmento óseo.

- Técnica quirúrgica.

Las ODI permiten realizar los mismos procedimientos que con las osteotomías completas, mediante las mismas vías de acceso pero el orden de ejecución va de proximal a distal, para ir corrigiendo la deformidad digital (Figura 12).

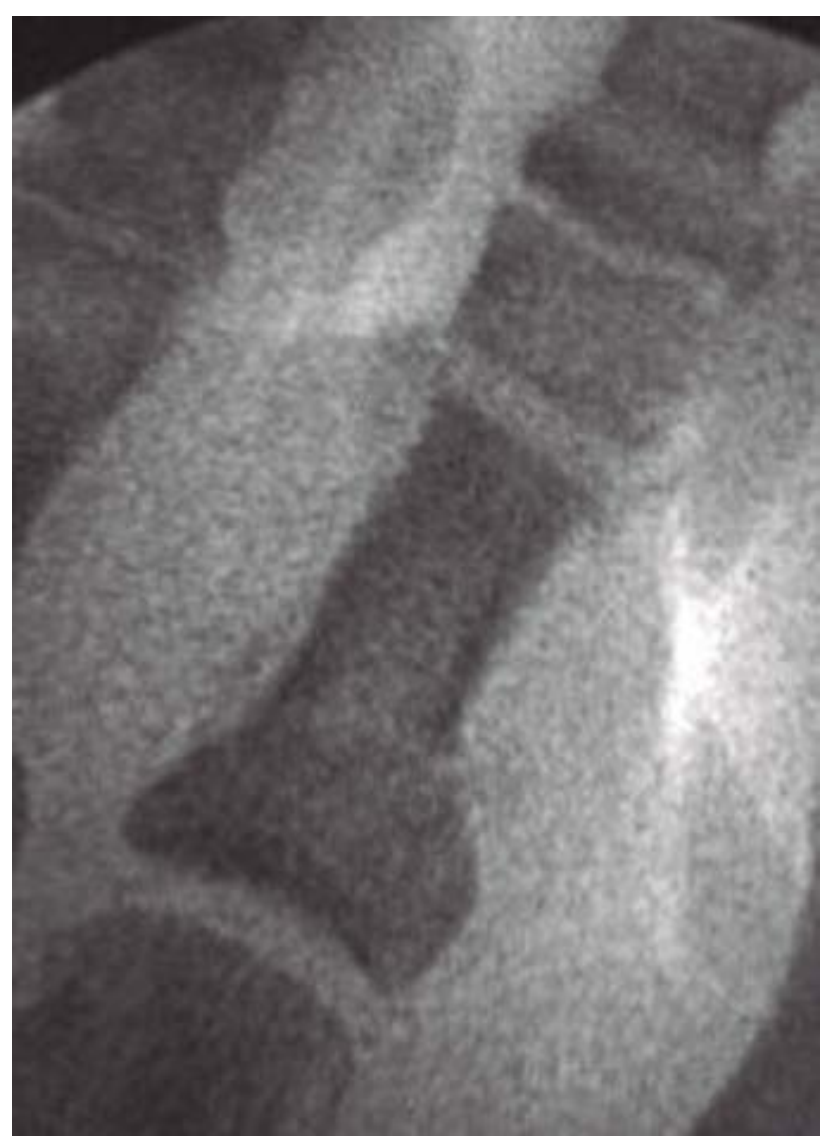

Figura 10. Imagen de triple osteotomía completa. 


\section{Artroplastia}

La artroplastia es un procedimiento habitual en la cirugía digital y probablemente en abierta sea el de excelencia. En la MIS tiene también cabida con sus indicaciones y cuya técnica fue descrita originariamente por el podiatra el Dr. Strauss ${ }^{9}$ en la década de los ochenta, dándole el nombre inicial a la técnica de S-toe y siendo importada a España por el podólogo el Dr. J. Aguilar, realizando su primera publicación en el noventa y ocho ${ }^{10}$.

Posteriormente, podólogos cirujanos como los Dres. C. Lerma $^{11}$, E. Nieto ${ }^{12}$ y J. Lozano ${ }^{13,14}$, ayudaron a difundir esta técnica en diversas publicaciones y ponencias.

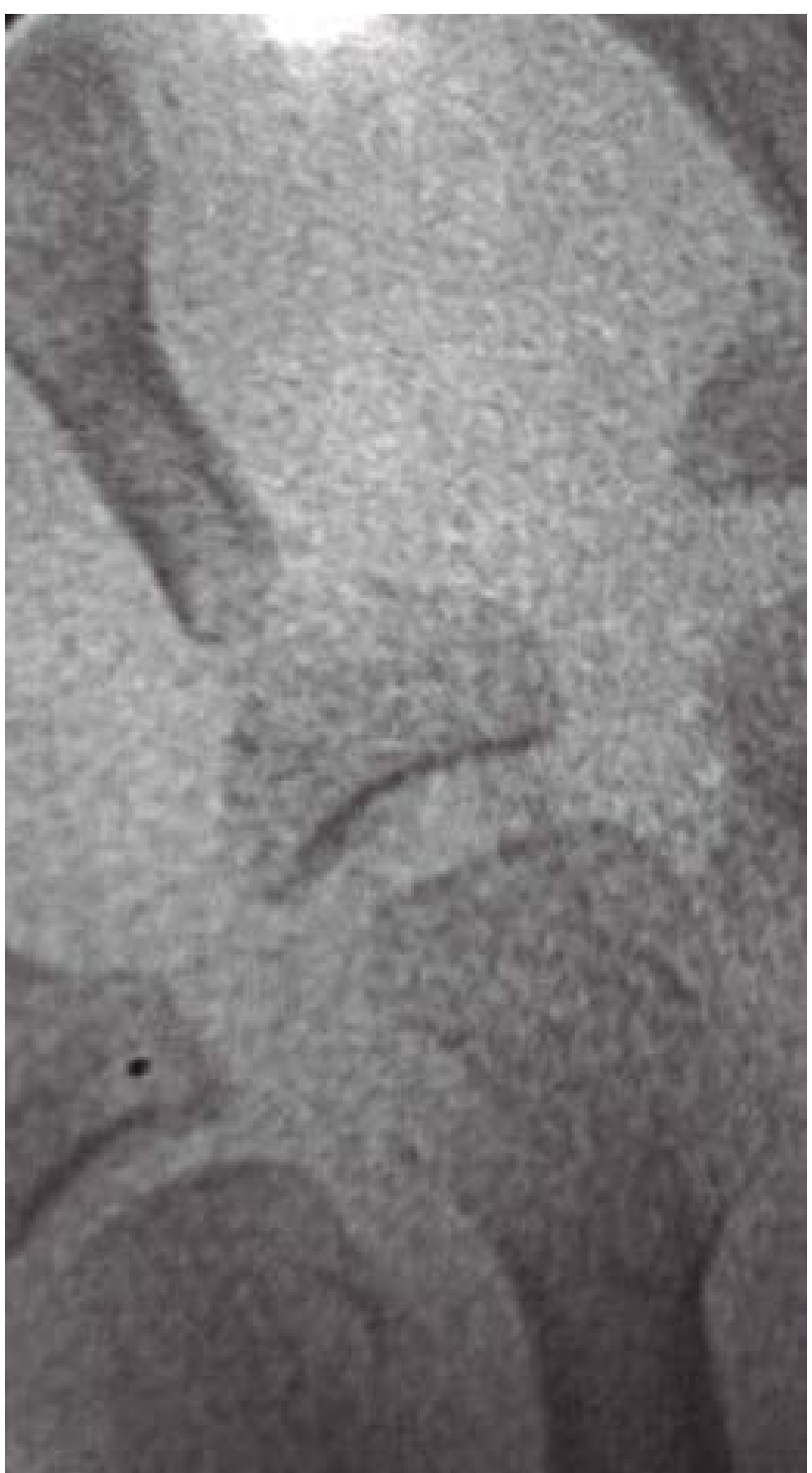

Figura 11. Imagen de doble osteotomía completa en falange proximal.
Indicación

La justificación que le damos a esta técnica es especialmente cuando nos encontramos una hipertrofia de la cabeza de la falange proximal, dedo hiperlongo, normalmente con queratopatía presente y su grado de deformidad es semirreductible. En caso de ser una articulación viable sugerimos optar por la técnica de osteotomías.

El objetivo es la resección de la cabeza de la falange proximal a nivel del cuello quirúrgico, presentando la ventaja que preserva íntegras las estructuras tendinosas a dicho nivel, favoreciendo una mayor estabilización y postoperatorio más liviano por minimizar el daño tisular, no precisar sutura intrínseca ni elementos de osteosíntesis.

\section{Técnica quirúrgica}

1. Se procede con una incisión (bisturí Beaver 64) latero-lateral con corte longitudinal de unos $5 \mathrm{~mm}$, iniciándola desde la articulación IFP hacia proximal, seccionando la cápsula y pegados a hueso, liberando las adherencias a nivel dorsal hasta cuello quirúrgico.

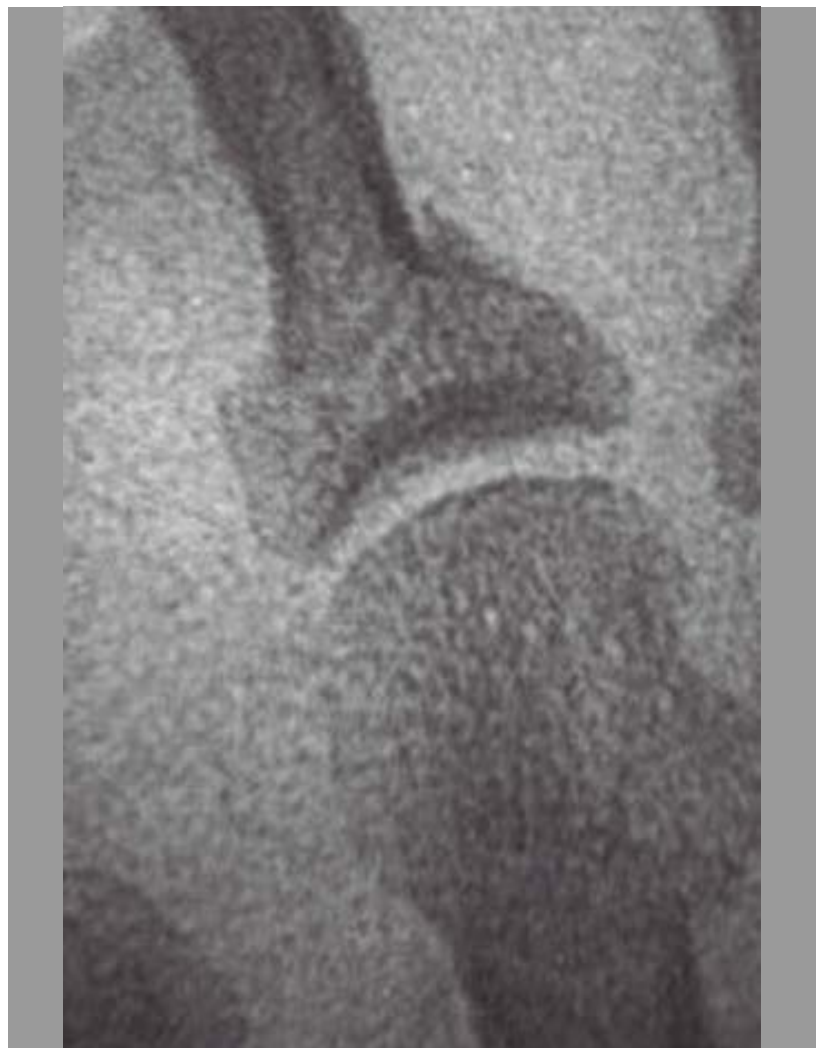

Figura 12. Imagen de osteotomía incompleta en base de falange proximal. 
2. Sin retirar el bisturí, se secciona el ligamento interfalángico mediante un giro del mismo con un corte transversal, pudiendo introducir la hoja intrarticularmente para la sección del ligamento contralateral mediante tracción distal del dedo con la mano pasiva. En caso de dificultad realizar esta segunda maniobra con el propio escoplo recto cuya parte distal tiene corte (Figura 13).

3. Con un escoplo de corte recto se delimita la cabeza en su porción dorsal, a nivel lateral y plantar (quedando la parte contralateral sin acceso). Como variante, si tuviéra- mos dificultad en la delimitación articular aconsejamos pasar la fresa intrarticular para facilitar la maniobra de extracción de la cabeza.

4. Delimitada correctamente la cabeza en sus 3 cuadrantes accesibles. Introducimos la fresa Shannon media para proceder a la osteotomía completa a nivel del cuello quirúrgico (Figura 14).

5. Con un mosquito fino pinzamos la cabeza y realizaremos movimientos rotacionales para facilitar su extracción, pudiendo ayudarnos con el bisturí para cortar adherencias (Figura 15).

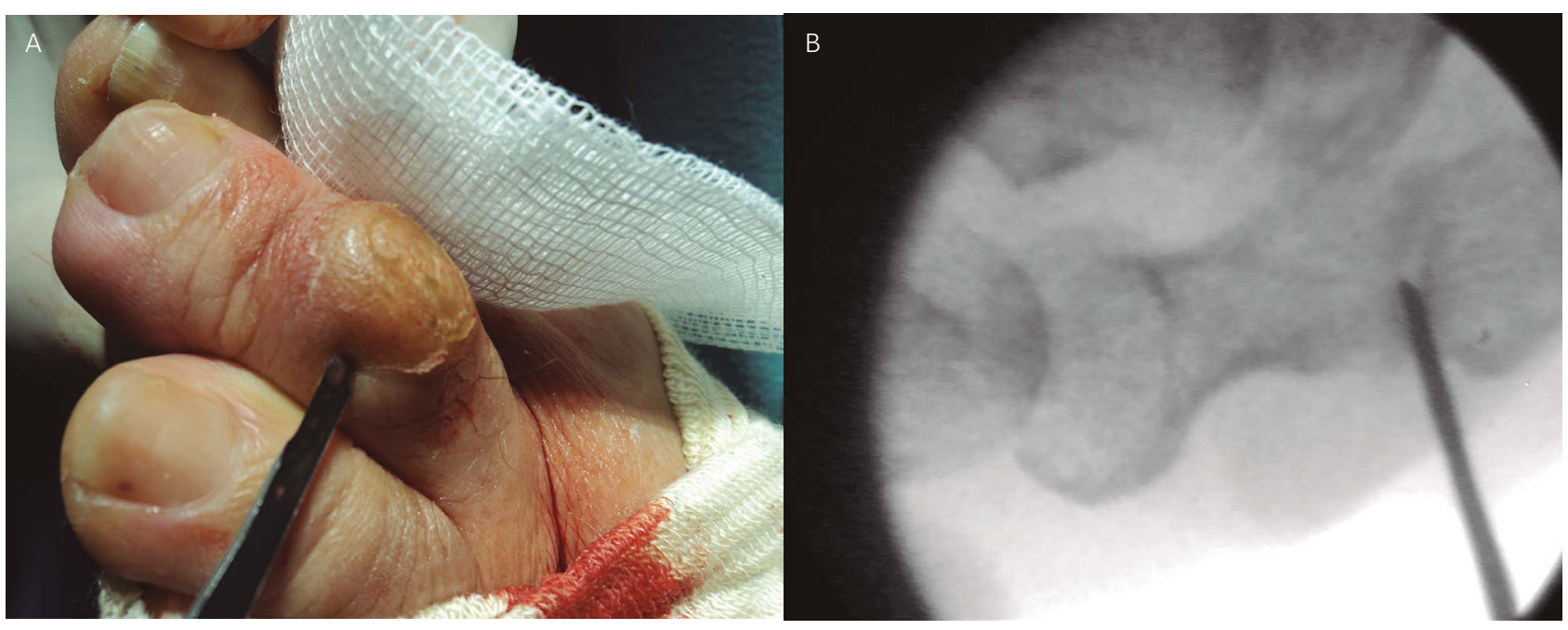

Figura 13. Incisión con bisturi Beaver 64 y sección ligamento interfalángico.

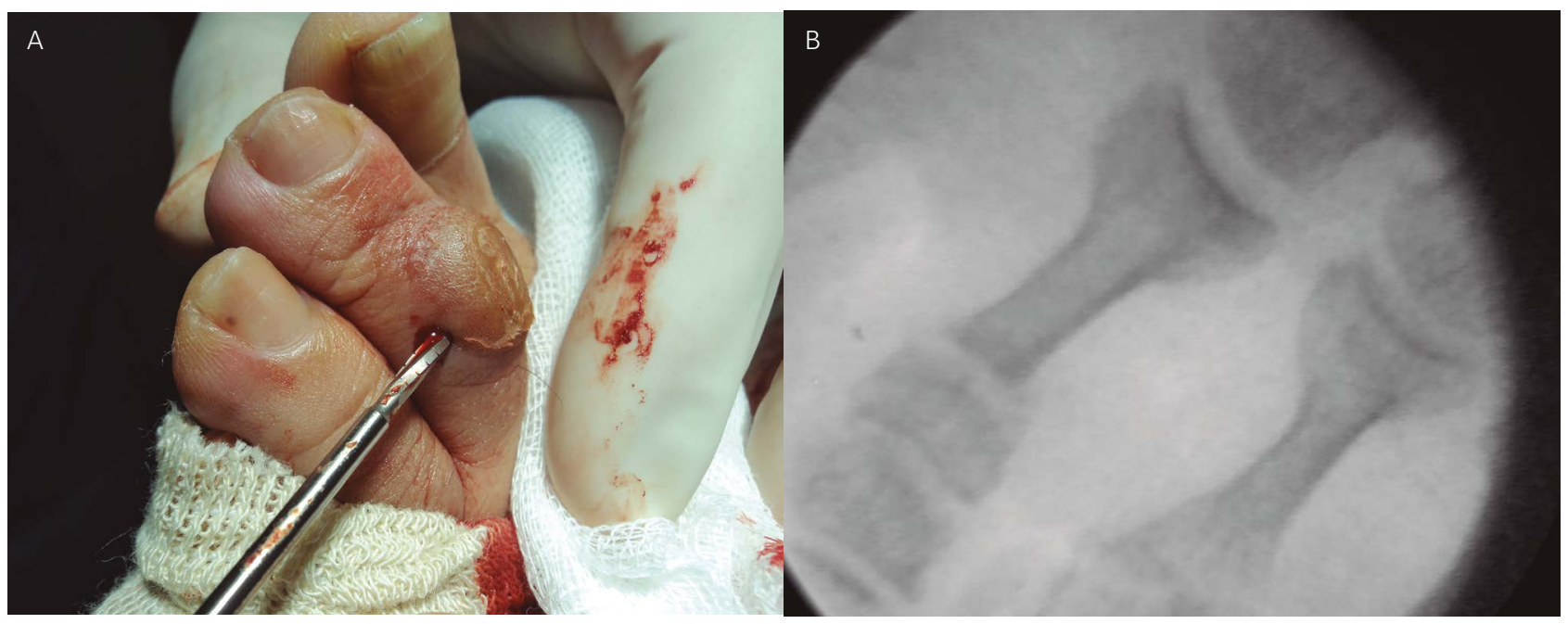

Figura 14. Introducción de la fresa Shannon media y osteotomía completa a nivel cuello quirúrgico de la cabeza de la falange proximal. 


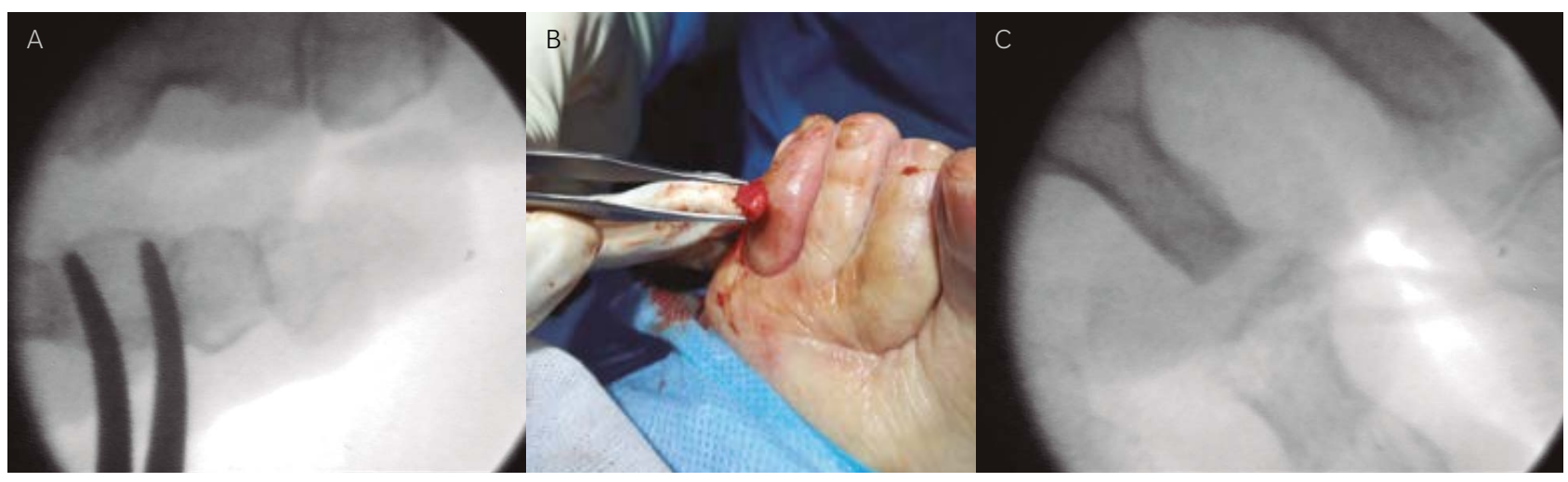

Figura 15. Con ayuda del fluoroscopio pinzamos la cabeza osteotomizada para su extracción y posterior comprobación de la artroplastia.

\section{Evolución}

Se mantiene el vendaje y calzado postoperatorio durante 4-6 semanas según evolución. Se generará una pseudoarticulación con rigidez o movilidad limitada.

\section{Artrodesis}

Este procedimiento tiene el objetivo de eliminar las cariIlas articulares y fusionar los dos fragmentos óseos residuales, suprimiendo así la articulación existente mediante el contacto de hueso esponjoso ${ }^{15}$.

\section{Indicación}

Su principal indicación (como el dedo en martillo, dedo en maza, entre otras) será en las deformidades rígidas, donde la viabilidad articular no merece la pena y con componentes asociados de enfermedades sistémicas con afectación osteoarticular que nos puedan condicionar a la fusión articular para evitar así posibles recidivas futuras y/o estadios de dolor inflamatorio articular ${ }^{1,8}$.

La deformidad se clasifica en un estadio de rigidez e irreductibilidad avanzada, o con una anquilosis que en su conjunto hace que la manipulación articular sea inaccesible o muy dificultosa, haciendo en esta diferenciación, la indicación de esta técnica en vez de la artroplastia. A diferencia de la artroplastia, no pretendemos generar una nueva pseudoarticulación, sino eliminarla y fusionarla manteniendo una rigidez completa entre los segmentos. Al igual que la artroplastia no precisa de osteosíntesis, ni sutura interna y su vía de acceso es de 1-2 mm, no precisando de punto de sutura (Figura 16).

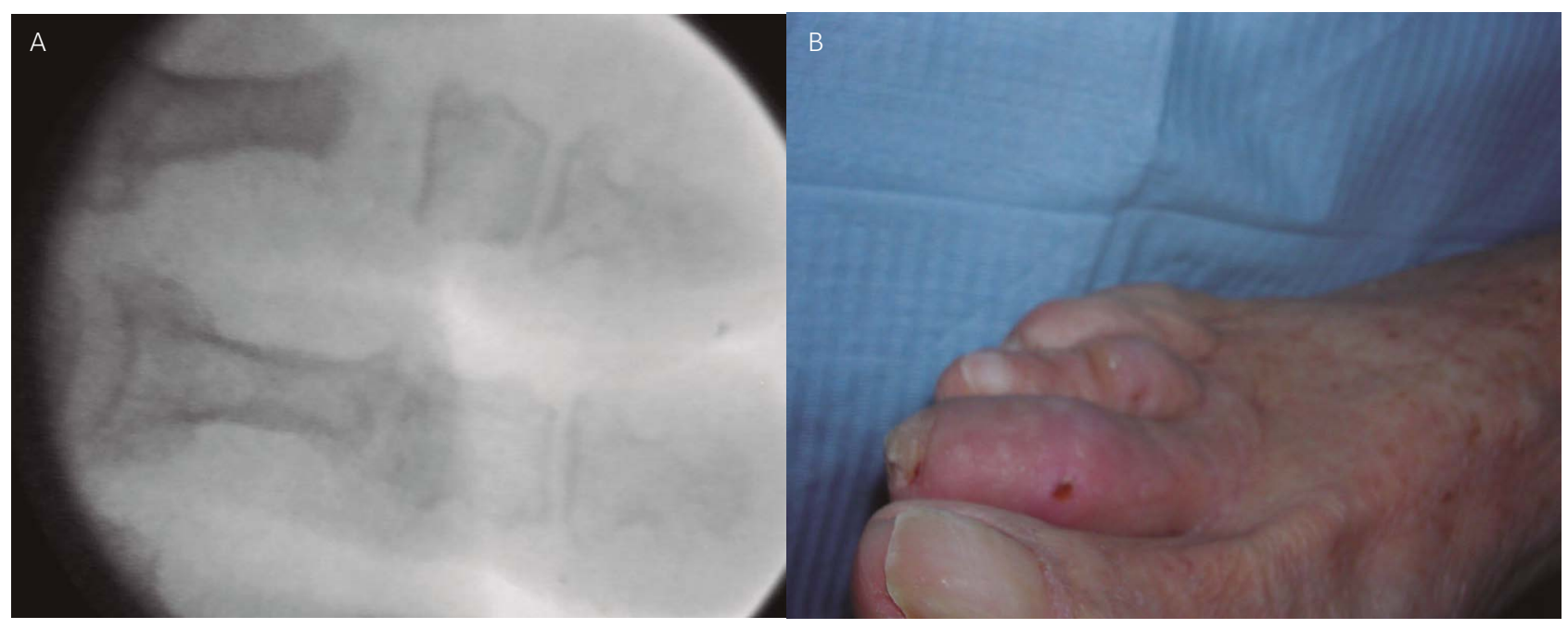

Figura 16. A. Imagen fluoroscópica comparativa entre artroplastia y artrodesis por MIS. B. Daño tisular de la incisión. 


\section{Técnica quirúrgica}

1. Su vía de acceso será mediante incisión longitudinal latero-dorsal y directamente sobre la articulación a actuar, ya sea la IFP o IFD según la patología existente y preservando los tendones flexores y extensores a este nivel, ya que estos elementos nos van a producir una mayor estabilización e impactación de los fragmentos.

2. Con un osteotomo delimitamos partes blandas del tejido óseo (preservando los extensores) y directamente introducimos una fresa tipo Shannon media sobre la línea articular abarcando su extensión dorsal.

3. Con fresado de arriba abajo eliminamos completamente las carillas articulares, así como la hipertrofia ósea existente hasta conseguir la corrección apropiada, pudiendo generar una cuña con vértice que propicie una mayor corrección a la deformidad digital presente. Para ello, el gesto de cierre la mano pasiva juega un papel muy importante, aumentando más o menos la cuña correctora. Se mantiene la pasta ósea interna que servirá de cemento óseo autógeno, favoreciendo por principio de consolidación la fusión entre los fragmentos.

4. Procedemos a la realineación del dedo y compactaremos los fragmentos con el vendaje apropiado.

La indicación de las técnicas digitales por MIS se encuentra en la Tabla II.

\section{DISCUSIÓN}

Las técnicas de osteotomías digitales por MIS se pueden aplicar tanto en la deformidad del dedo en martillo, dedo en maza, dedo en garra, clinodactilias como en otras deformidades en el plano axial, tal y como describe y justifica minuciosamente J. A. Teatino en su publicación ${ }^{16}$. Con estos procedimientos actuamos en la deformidad, restaurando la posición planar de los segmentos óseos sin la necesidad de destruir una articulación viable, actuando sobre los vectores de fuerza que constituyen las leyes de Wolf y Jones ${ }^{17}$; estas técnicas son reafirmadas por autores como M. de Prado ${ }^{18}, \mathrm{C}$. Naranjo ${ }^{19}$ $y$, posteriormente, E. Nieto lo complementa con las técnicas de ODI aportando una mayor estabilidad de la osteotomía al mantener un vértice intacto $8,9,20$.

En la deformidad digital se emplea con frecuencia el término dedo en garra o en martillo, si bien se ha descrito su diferenciación. En la mayoría de la literatura las técnicas habituales descritas son en especial la artroplastia y la artrodesis para las deformidades semirrígidas o rígidas ${ }^{1,21-24}$, siendo imprescindible la valoración de la implicación del hallux, así como la actuación en la realineación MTTF, actuando si procede en dichas estructuras, independientemente de que se empleen técnicas MIS o abiertas. La artroplastia y artrodesis son técnicas que pueden realizarse por cirugía mínimamente invasiva con los procedimientos descritos anteriormente ${ }^{7-12}$.
Tanto en la artroplastia como en la artrodesis por MIS podemos respetar las estructuras tendinosas, ya que su vía de acceso no precisa la sección o actuación sobre las mismas, favoreciendo una estabilización intrínseca que, junto con el vendaje y calzado postquirúrgico, podrían hacer innecesaria la utilización de elementos de estabilización con osteosíntesis, por lo que estas técnicas podrían ser una primera opción quirúrgica en la cirugía digital. La mayoría de los artículos publicados sobre artroplastia y artrodesis son de cirugía a campo abierto (lo cual evidencia que son los procedimientos más generalizados en la cirugía digital) si bien la cirugía MIS precisa de más publicaciones al respecto para respaldar sus buenos resultados.

Nieto y cols. afirman que las osteotomías incompletas para la corrección de las deformidades digitales ofrecen mayor estabilidad, menor inflamación, un callo óseo más pequeño y un menor tiempo de recuperación al haber menor movimiento interfragmentario respecto a las osteotomías completas, donde existe mayor inflamación y dolor postquirúrgico, junto con un callo óseo de mayor volumen debido al mayor movimiento interfragmentario, alargando el periodo postquirúrgico ${ }^{19,20}$.

Igualmente, Nieto y cols. confirman la importancia de los vendajes específicos en este tipo de osteotomías como elemento de fijación externo para mantener el cierre de la osteotomía y la corrección del de la deformidad digital.

Otros autores consideran que las osteotomías incompletas tienen una indicación específica para aquellas deformidades digitales, leves o moderadas, y sin afectación articular, mientras que las osteotomías completas estarían indicadas en aquellas deformidades severas y estructuradas en las que se debería acompañar previamente de técnicas sobre tejido blando ${ }^{25-27}$.

Nieto y cols., en el estudio realizado sobre 730 osteotomías incompletas, afirman que la curva de aprendizaje de las osteotomías incompletas es larga, pues cuanto mayor sea la destreza del cirujano mayor es el grado de satisfacción en el tratamiento de las deformidades digitales mediante las osteotomías incompletas ${ }^{20}$.

Algunos autores se decantan por la realización de osteotomías completas para las deformidades de dedos en garra y omitir las tenotomías, produciendo una relajación tendinosa al acortar el segmento óseo y, por lo tanto, se mantiene la movilidad activa del dedo ${ }^{19,25}$.

En la literatura existen diferentes estudios que comparan resultados entre cirugía MIS o percutánea respecto a la abierta, en los que se muestran mejores resultados a favor de las técnicas MIS.

Otros autores ${ }^{28,29}$, teniendo en referencia la escala visual analógica del dolor (VAS), encuentran mejores valores en la cirugía percutánea $(2,5)$ respecto a la cirugía abierta $(3,5)$. También publican, en cuanto a las complicaciones producidas por infección postquirúrgica en cirugía digital, mejores valores para la cirugía percutánea: en una muestra de 675 dedos intervenidos describen una incidencia de infecciones de 2,2 \% en percutánea y del 5,3\% en abierta. En su estudio 
Tabla II. Indicación de técnicas digitales por MIS.

\begin{tabular}{|c|c|c|c|}
\hline Procedimiento & Tipo de deformidad & Vía de acceso y actuación & Objetivo principal \\
\hline Tenotomía EL y EC & Subluxación MTTF & $\begin{array}{l}\text { Sobre la línea articular } \\
\text { de la MTTF (recordar que } \\
\text { el EC pasa lateral al EL y requiere } \\
\text { tenotomía por separado) o sobre } \\
\text { la base dorsal de la FP donde } \\
\text { discurren conjuntamente }\end{array}$ & $\begin{array}{l}\text { Realineación y relajación dorsal } \\
\text { de la articulación MTTF } \\
\text { Actuación conjunta sobre EL y EC } \\
\text { en parte más distal de la MTTF } \\
\text { o sobre la MTTF para } \\
\text { preservación del EC }\end{array}$ \\
\hline Tenotomía FL y FC & Dedo en garra, martillo & $\begin{array}{l}\text { A nivel plantar sobre la base } \\
\text { de la FP }\end{array}$ & $\begin{array}{l}\text { Relajación fuerzas deformatorias } \\
\text { plantares falange media y distal }\end{array}$ \\
\hline Tenotomía FC & Dedo en maza & $\begin{array}{l}\text { A nivel plantar de la } \\
\text { interfalángica distal }\end{array}$ & $\begin{array}{l}\text { Relajación fuerzas deformatorias } \\
\text { plantares sobre la tercera falange }\end{array}$ \\
\hline $\begin{array}{l}\text { Legrado óseo y/o } \\
\text { osteotripsia }\end{array}$ & $\begin{array}{l}\text { Exostectomías, remodelación } \\
\text { irregularidades óseas de la } \\
\text { deformidad presente }\end{array}$ & Según localización presente & $\begin{array}{l}\text { Procedimiento complementario } \\
\text { para remodelar la deformidad } \\
\text { presente }\end{array}$ \\
\hline Osteotomía simple & $\begin{array}{l}\text { Deformidad reductible, } \\
\text { clinodactília } \\
\text { supra- o infraducción }\end{array}$ & $\begin{array}{l}\text { A nivel plantar sobre la base } \\
\text { de la FP }\end{array}$ & $\begin{array}{l}\text { Deformidad simple y corrección } \\
\text { en uno o varios planos }\end{array}$ \\
\hline Osteotomía doble & $\begin{array}{l}\text { Deformidad semirreductible, dedo } \\
\text { garra, dedo martillo, clinodactiilia, } \\
\text { infra- o supraducción }\end{array}$ & $\begin{array}{l}\text { A nivel plantar sobre la base } \\
\text { de la FP y dorsal sobre cuerpo } \\
\text { medio de la falange media }\end{array}$ & $\begin{array}{l}\text { Deformidad moderada } \\
\text { y corrección en varios planos } \\
\text { si precisa }\end{array}$ \\
\hline Osteotomía triple & $\begin{array}{l}\text { Deformidad irreductible, } \\
\text { dedo hiperlongo }\end{array}$ & $\begin{array}{l}\text { A nivel plantar sobre la base } \\
\text { de la FP, dorsal sobre el cuello FP } \\
\text { y dorsal sobre cuerpo medio de } \\
\text { la falange media }\end{array}$ & $\begin{array}{l}\text { Deformidad severa y corrección } \\
\text { en diferentes planos }\end{array}$ \\
\hline Artroplastia & $\begin{array}{l}\text { Deformidad semirreductible, } \\
\text { la viabilidad articular no merece la } \\
\text { pena, dedo garra, dedo martillo, } \\
\text { hipertrofia de la cabeza FP }\end{array}$ & $\begin{array}{l}\text { Incisión lateral desde la línea } \\
\text { articular de la IFP hacia proximal } \\
\text { de } 5-7 \mathrm{~mm}\end{array}$ & Exéresis de la cabeza de la FP \\
\hline Artrodesis & $\begin{array}{l}\text { Deformidad rígida, } \\
\text { dedo martillo, dedo garra, } \\
\text { dedo maza }\end{array}$ & $\begin{array}{l}\text { Incisión lateral de } 2 \text { mm sobre } \\
\text { la línea articular de la IFP y/o IFD }\end{array}$ & $\begin{array}{l}\text { Eliminación carillas articulares } \\
\text { y fusión de las mismas para } \\
\text { la corrección digital en los planos } \\
\text { requeridos }\end{array}$ \\
\hline
\end{tabular}

encontraron una deformidad recurrente del 6,2\% en abierta fijada con aguja-K respecto al 2,26 \% de percutánea ${ }^{30}$.

\section{CONCLUSIONES}

La cirugía por mínima incisión es una opción resolutiva y segura para el tratamiento de las deformidades de los dedos menores. Presenta una buena aceptación por parte del paciente al ser menos invasiva, disminuir complicaciones por infección y dejar menos cicatriz en la piel.

La artrodesis y la artroplastia son técnicas que se pueden realizar mediante MIS con el objetivo de producir una fusión de la articulación en la artrodesis, indicada principalmente en deformidades rígidas, y una pseudoarticulación en la segunda, mediante la exéresis de la cabeza de la falange aplicable en deformidades semirrígidas mediante una vía de acceso mínima respetando en ambos casos las estructuras tendinosas que van a ayudar a la coaptación de los segmentos óseos restante y van a dar estabilidad durante el periodo postquirúrgico, prescindiendo de elementos de osteosíntesis.

Las ODI son las técnicas de elección en aquellas deformidades digitales leves o moderadas sin afectación articular, en las que se ofrece una mayor estabilidad interfragmentaria, disminuyendo la inflamación y el dolor postoperatorio, acortando el periodo postquirúrgico.

Las osteotomías completas están indicadas en aquellas deformidades digitales severas y estructuradas, pudiendo ir 
o no acompañadas de actuaciones sobre las estructuras tendinosas, para preservar la movilidad inicial del dígito.

Los diferentes procedimientos de técnicas digitales por MIS pueden ser combinados y complementados entre sí para la resolución de la deformidad.

Las actuaciones exclusivas sobre partes blandas han de estar justificadas.

\section{BIBLIOGRAFÍA}

1. Buterrworth R, Dockery GL. Atlas a color y texto de cirugía del antepié. Madrid: Ed. Ortocen; 1992.

2. Nieto García E, coordinador Cirugía podológica. Técnicas por mínima incisión. Madrid: Ed. Mileto; 2004.

3. Nieto García E (coord.). Cirugía mínimamente invasiva del pie. Barcelona: Ed. Glosa; 2017.

4. Kellikian AS. Tratamiento quirúrgico de pie y tobillo. México DF: McGraII-Hill interamericana de México; 2001.

5. Yu GV, Judge MS, Hudson JR, Seidelmann FE. Predislocation Syndrome. Progressive Subluxation/Dislocation of the Lesser Metatarsophalangeal Joint. J Am Podiatr Med Assoc. 2002;92(4):182-99.

6. Bycura Blair M. Bycura on minimal incision surgery. USA: Ed.Weissman; 1986.

7. Teatino JA. Cirugía por mínima incisión en los dedos medios. Rev Podoscopio. 1995;20.

8. Nieto García E, Ramírez Andrés L, Nieto González E. Técnicas ODI en cirugía de mínima incisión. Rev Esp Podol. 2007;18(1):22-8.

9. Lozano Freixas J. Artroplastia S-toe. Artrodesis por mínima incisión. En: Cirugía mínimamente invasiva del pie. Nieto García E, coord. Barcelona: Ed. Glosa; 2017. p. 85-7.

10. Aguilar Beltrán J. Artroplastia en un dedo del pie por mínima incisión. Rev El Peu 1998;75.

11. Lerma Barragan C. Artroplastia por MIS. Rev. Podoscopio 2002;17:14-8.

12. Nieto E, Ramírez L, Nieto García E. Artroplastia S-toe por mínima incisión. Rev Podomorfos 2001;1(3). Disponible en http://www.nursingworld.org.

13. Lozano Freixas J. Artroplastia por mínima incisión. Revista El Peu. 2012;32:24-7.

14. Lozano Freixas J. Artroplastia por mínima incisión en el dedo en martillo. Rev Esp Podol. 2009;20(6):252-5.

15. Alcalá SanzJ. Artrodesis digital. Revisión histórica y sistemas de fijación. Rev Esp Podol. 2013;24(2):56-61.
16. Teatino JA. Cirugía por mínima incisión en los dedos medios. Rev Podoscopio. 1995;(20).

17. Nieto García E. Osteotomías digitales incompletas. Técnicas ODI. En: Nieto García E. Cirugía mínimamente invasiva del pie. Barcelona: Ed. Glosa; 2017. p. 101-11.

18. De Prado M, Golano P, Ripoll P. Cirugía percutánea del pie. Barcelona: Ed. Masson; 2003

19. Naranjo Ruiz C. Elección de las técnicas de mínima incisión en el tratamiento quirúrgico de los dedos medios. Rev Podoscopio. 2010;(47):786-92.

20. Nieto García E, Ramírez Andrés L, Nieto González E. Diseño de las osteotomías digitales incompletas: técnicas ODI. Rev Esp Podol. 2012;23(1):9-15.

21. Coughlin MJ, Dorris J. Operative repair of the fixed hammer toe deformity. Foot Ankle 2000;21(2):94-104.

22. Myerson MS, Shereff MJ. The pathological anatomy of claw and Hammer Toes. J Bone Joint Surg Am 1989;71(1):45-9.

23. Caterini R, Farsetti P, Tarantino U. Arthrodesis of the toe joints UIT an intramedullary cannulated screwfor correction of hammer toe deformity. Foot Ankle Int 2004;25(4):256-61. DOI: 10.1177/107110070402500411.

24. Pastrana García F, Olivares Gutiérrez J, Bárcena Jiménez LR, Fuentes Nucamendi MA. Tratamiento de la deformidad en garra de los dedos menores del pie. Acta ortopédica mexicana. 2008;22(3):189-94.

25. Isham SA, Nunez OE. Isham hammertoe procedures for the correction of lesser digital deformities: Phalangeal osteotomy procedures. En: Maffulli N, Easley M. Minimally invasive forefoot surgery in clinical practice. $1^{\text {a }}$ ed. Londres: Springer; 2013. p. 161-79.

26. Solan MC, Davies MS. Revision surgery of the lesser toes. Foot Ankle Clin. 2011;16(4):621-45. DOI: 10.1016/j.fcl.2011.09.002.

27. Myerson MS. Correction of lesser toe deformity. En: Kerala VP, Pallamparthy R, Myerson MS. Reconstructive foot and ankle surgery. $2^{\mathrm{a}} \mathrm{ed}$. Philadelphia: Elsevier Saunders; 2010. p. 97-108.

28. Haque S, Kakwani R, Chadwich C, Davies MB, Blundell CM. Outcome of minimally invasive distal metatarsal metaphyseal osteotomy (DMNO) for lesser toe metatarsalgia. Foot Ankle Int. 2016;37(1):58-63. DOI: 10.1177/1071100715598601.

29. Krenn S, Albers S, BockP, Mansfield C, CHraim M, Trnka HJ. Minimally invasive distal mettarsal metaphyseal osteotomy of the lesser toes: Learning curve. Foot Ankle Spec. 2018;11(3):263-8. DOI: 10.1177/1938640017750251.

30. Kramer WC, Parman M, Marks RM. Hammertoe correction withnk-wire fixation. Foot Ankle Int. 2015;36(5):494-502. DOI: $10.1177 / 10711007145568013$. 